\title{
AS POSSIBILIDADES DE (IN)SATISFAÇÃO NO TRABALHO DO SERVIDOR PÚBLICO
}

\section{ARTIGO DE REVISÃO}

VIOLA, José Raphael ${ }^{1}$

SCATOLIN, Henrique Guilherme ${ }^{2}$

VIOLA, José Raphael. SCATOLIN, Henrique Guilherme. As possibilidades de (in)satisfação no trabalho do Servidor Público. Revista Científica Multidisciplinar Núcleo do Conhecimento. Ano 05, Ed. 03, Vol. 08, pp. 115-130. Março de 2020. ISSN: 2448-0959, Link de acesso: https://www.nucleodoconhecimento.com.br/psicologia/trabalho-do-servidorpublico

\section{RESUMO}

O presente trabalho tem por objetivo pesquisar sobre os elementos geradores de satisfação e insatisfação no âmbito do trabalho público, para desta forma identificar os elementos que levam os servidores a atingir tais estados emocionais. Desta forma pretende-se evidenciar se é possível obter satisfação trabalhando em órgãos públicos, ou se estes são geradores de insatisfação devido aos seus métodos organizacionais. Este trabalho possui os servidores públicos como foco de pesquisa, pois estes trabalhadores não partilham dos mesmos elementos funcionais da iniciativa privada. Para a realização da pesquisa foi utilizado o método de revisão bibliográfica, qualitativa e exploratória, buscando dados em artigos publicados na base de dados online, Scielo, com os descritores "trabalho e satisfação" e "trabalho e insatisfação", sendo atribuídos como fatores de inclusão os artigos com menos de cinco anos de

\footnotetext{
${ }^{1}$ Especialista em Psicologia do Trabalho e Organizacional, Graduado em Psicologia pela $\mathrm{FHO}$ - Uniararas.

2 Doutor em Psicologia.
} 
publicação e disponíveis na integra em português. Com este método se teve o intuito de compreender o que vem sendo publicado sobre satisfação e insatisfação e, utilizar estas informações buscando atingir a problemática desta pesquisa, de forma a desenvolver a aproximação com o tema proposto e facilitar a reflexão sobre as instituições públicas e, o como estas afetam a vida laboral de seus servidores. Sendo, por fim, possível concluir que a satisfação e insatisfação são elementos subjetivos que podem se apresentar por diferentes fatores em diferentes indivíduos, porém se demonstra como principal fator de satisfação o reconhecimentos e de insatisfação o salário e falta de condições favoráveis para a realização do trabalho.

Palavras-chave: Trabalho, satisfação, insatisfação.

\section{INTRODUÇÃO}

Para iniciar este trabalho é necessário primeiramente discutir como se chegou ao tema sugerido, assim como a problemática de pesquisa a qual se pretende atingir. $A$ priori tinha-se por intenção pesquisar a (des)motivação no ambiente de trabalho do servidor público, relacionando este elemento a qualidade de vida deste trabalhador já que este é um trabalho focado na área da saúde do trabalhador.

Entretanto, após pesquisa inicial, foi possível notar a diferenciação apresentada por alguns teóricos entre os termos motivação e satisfação. Desta forma passou-se a instaurar o segundo termo preferencialmente sobre o primeiro, pois como afirma Herzberg (1997), a motivação não necessariamente possui foco em elementos positivos, pois mesmo fenômenos punitivos podem fazer o trabalhador se motivar na busca de deixar de ser punido.

Lembrando que este trabalho visa à qualidade de vida do trabalhador, o termo motivação demonstrou não ser a melhor opção em escolha. Por outro lado, Hora, Ribas Júnior e Souza (2018) conceituam a satisfação na magnitude do quanto o trabalhador se aprazerá em suas atividades laborais. Assim, este conceito esta mais próximo daquilo que se é pretendido nesta pesquisa e sem excluir a terminologia anterior, já que segundo Pilatti (2012), a motivação é gerada a partir da ação para 
suprir uma necessidade, já à satisfação é algo que satisfaz a necessidade do individuo. Embora os conceitos sejam bastante próximos, e até mesmo complementares, é necessário compreender, por exemplo, que o trabalhador motivado tende a realizar suas funções desde que continuamente exposto aos estímulos que o motivam, já o trabalhador satisfeito realizará suas tarefas sendo seu próprio influenciador, até que sua satisfação deixe de ser saciada e retorne a necessitar de motivadores. Podemos assim compreender que "satisfação" não apenas está mais próximo do que se pretende pesquisar, como também engloba a "motivação" direta e indiretamente.

Ao que se refere ao público alvo pesquisado, os servidores públicos, estes indivíduos foram escolhidos por possuírem aspectos trabalhistas que os diferenciam dos trabalhadores da iniciativa privada, além de representar um número consideravelmente elevado de indivíduos, como demonstra o comunicado ํำ10 do IPEA (Instituto de Pesquisa Econômica Aplicada) uma vez que no ano de 2010 já existiam mais de nove milhões de trabalhadores públicos no Brasil, sendo $52 \%$ representados pelos servidores municipais. Esta informação pode ser complementada pelos dados retirados do site do Governo do Estado de São Paulo que aponta a existência de 339,161 mulheres trabalhando em órgãos estaduais no ano de 2017, o que representava na época um total de $52 \%$ dos servidores, apenas no estado se de São Paulo.

Sendo assim, pesquisar sobre um tema que abrange este imenso contingencial humano torna-se demasiadamente importante, principalmente ao que se refere à qualidade de vida do trabalhador, pois como acrescenta Tambasco et al. (2017), a (in)satisfação se relaciona aos processos de saúde do trabalhador, de tal forma que interfere diretamente nos aspectos sociais, familiares e na qualidade de vida do indivíduo.

Pelos fatores acima apresentados, este trabalho tem por conceito pesquisar as possibilidades de (in)satisfação na atuação dos servidores públicos, tendo por objetivo discutir os elementos geradores de satisfação e insatisfação para assim saber quais deles demostram-se existentes no campo de atuação destes profissionais, o que 
permitirá refletir o quão (in)satisfeito este público alvo está perante suas atividades laborais.

Como problemática de pesquisa, fundamentando-se nos autores acima referidos, este artigo pretende compreender como a insatisfação pode influenciar na qualidade de vida do servidor público, de forma a interferir em seu cotidiano e afetar o desenvolvimento de suas atividades laborais, assim minando a progressão dos mesmos e desestabilizando suas oportunidades de evoluir segundo os conceitos da meritocracia empregados pelos órgãos municipais, estaduais e federais.

Acrescentando sobre o método de evolução por meritocracia dito anteriormente, na problemática deste trabalho, podemos notar que este modelo de evolução trabalhista é existente no funcionalismo público brasileiro a partir da Lei n 9.527, do ano de 1997, a qual altera os dispostos na Lei $\mathrm{n}^{\circ} \mathbf{8 . 1 1 2}$, de 1990 e rege o funcionalismo dos servidores públicos civis da união, determinando respectivamente nos artigos n62 e $\mathrm{n} \div 67$, os servidores que atuarem em cargos de chefia, direção ou assessoria, sendo estes comissionados ou de natureza especial, serão devidamente retribuídos pelo exercício dos mesmos. E a cada cinco anos de efetivo exercício em serviço público, o servidor será retribuído e um total de cinco por cento sobre seu vencimento básico, respeitando um limite máximo de trinta e cinco por cento.

Corroborando com estes dados temos a Lei ํㅜ 10.098 de 1994, que dispõem sobre o estatuto do servidor público do estado do Rio Grande do Sul, o qual determina em seu artigo no 36 que as promoções funcionais devem ocorrer de grau a grau, alternadamente, respeitando os critérios de merecimento e antiguidade. Esta legislação está ainda de acordo com a existente no estado de São Paulo sobre o funcionalismo público, sendo a Lei n 10.26 de 1968, que dispõem em seu artigo no 87, ser a promoção a passagem de grau dentro da mesma classe respeitando critérios de antiguidade e merecimento, alternadamente. E completa com o artigo no 88, dizendo que o merecimento deve ser avaliado em pontos negativos e positivos.

Desta forma fica claro a aplicação da meritocracia no território brasileiro, de tal forma que demonstra a importância de se verificar as relações deste método e condições de 
trabalho no processo de satisfação e insatisfação dos indivíduos que atuam sobre as legislações que regem as instituições públicas. Lembrando ainda que a insatisfação pode prejudicar o modelo de avaliação de progressão dos servidores públicos, assim como sua qualidade de vida no trabalho e acabar também por interferir na qualidade dos serviços ofertados para a população através das instituições públicas.

\section{METODOLOGIA}

Para atingir o objetivo deste trabalho, a metodologia empregada foi a pesquisa bibliográfica e exploratória. Sobre este método é possível afirmar que se trata de uma pesquisa realizada a partir do levantamento de dados em bases bibliográficas, utilizando-se materiais já publicados, buscando a relação entre o fenômeno estudado com o mundo real, assim visando a sua aproximação e discussão, com o intuito de tornar os elementos trabalhados mais próximos ao âmbito teórico e prático, fomentando a possibilidade de criação de hipóteses e também familiaridade com o que se é discutido (SILVA e MENEZES, 2005; SILVEIRA e CÓRDOVA, 2009; SOUZA et. al., 2013). Foram utilizadas bases de dados online para pesquisa dos descritores "satisfação e trabalho", assim como "insatisfação e trabalho". Com os resultados encontrados, foi realizado um paralelo entre o que é (in)satisfação e os elementos que levam o trabalhador a atingir tal estado. Estes conceitos foi unidos à discussão acerca das condições de trabalho dos servidores públicos, para assim se chegar a conclusões sobe a possibilidade ou não de (in)satisfação neste meio de atuação e como estes fatores interferem na vida laboral dos servidores.

Para a realização da coleta de dados estipulou-se como instrumento de pesquisa o Scielo, por entender que este se trata de uma das principais bases de dados online acessados para pesquisa de materiais científicos. Utilizando esta base de dados pesquisou-se como descritores os termos "trabalho e satisfação" e "trabalho e insatisfação", ficando determinado como critério de seleção dos artigos aqueles que apresentavam ambos os termos em seu título, assim como os que disponibilizavam o texto na integra em português. Foram excluídos os artigos publicados a mais de cinco anos, os que não possuíam publicação na integra em português ou não apresentavam ambos os termos na titulo do artigo. Com esta metodologia obteve-se com o primeiro 
descritor, satisfação e trabalho, um total de 73 artigos, porém deste foram excluídos os quais possuíam mais de cinco anos desde a data de sua publicação, reduzindo assim para um total de 27 artigos. Com o segundo descritor, insatisfação e trabalho, foi atribuído o mesmo método de seleção e exclusão, obtendo-se 3 artigos, totalizando assim 30 artigos encontrados com ambos os descritos.

Com os dados previamente coletados e após a leitura na integra de todos os artigos, pode-se notar a existência de 2 artigos encontrados com ambos os descritores, assim reduzindo o número total a 28 artigos. Destes, ainda, 4 foram excluídos por se entender que não se enquadravam no contexto desta pesquisa, pois não relacionavam a (in)satisfação ao ambiente de trabalho formal, seja de instituições privadas ou públicas. Desta forma restando um total de 24 artigos que foram utilizados para o desenvolvimento desta pesquisa, pretendendo-se assim atingir a problemática deste estudo.

\section{DISCUSSÃO}

Para iniciar esta discussão vale frisar a relevância do cotidiano laboral sobre o dia a dia do trabalhador público, de tal forma que as atividades e elementos presentes no mundo do trabalho interferem diretamente na saúde e nos aspectos sociais do individuo que trabalha (TAMBASCO et al., 2017). Assim entende-se que indivíduos mais satisfeitos em ambiente de trabalho tornam-se menos suscetíveis a processos de adoecimento físico e mental e possuem melhor qualidade de vida (FORTE e PIRES, 2017).

É preciso conceituar que os elementos de (in)satisfação podem variar devido a subjetividade de cada individuo, de forma a não apresentar elementos padrões, fato que segundo Souza, Milani e Alexandre (2015) torna a delimitação do assunto algo bastante complexo. Porém conhecer os elementos geradores de (in)satisfação podem despertar uma luz sobre quais aspectos do mundo do trabalho merecem maior atenção por parte dos gestores. 
Em um conceito superficial, pode-se dizer em um primeiro momento, que a satisfação está ligada simplesmente ao quanto um trabalhador gosta das atividades que realiza (HORA; JÚNIOR e SOUZA, 2018). Contudo, alguns dos elementos de (in)satisfação presentes no mundo do trabalho que podem ser mencionados segundo Tambasco et al. (2017); Sá; Martins-Silva e Funchal (2014); Soratto et al. (2017), são a qualificação profissional, salário, não reposição de pessoal, rotatividade, ambiente físico, jornada de trabalho e reconhecimento profissional.

Focando nas instituições púbicas é possível ainda acrescentar, segundo Traesel e Merlo (2014), o processo de precarização gerado pela terceirização que vem sendo implantada neste setor, junto à sobre carga os procedimentos laborais que estão focados na realização das tarefas sem interesse na pessoa que o realiza, são fatores que vem gerando insatisfação nos servidores públicos. Acrescentando ainda os elementos de insatisfação no setor público, temos os salários e sistemas de recompensa que não atingem as expectativas dos servidores e levam estes a um processo de desmotivação (MARQUES; BORGES e REIS, 2016).

Dificultando, ainda, a busca por satisfação dos funcionários públicos, além de todos os desafios vivenciados no dia a dia do trabalho, temos o engessamento dos métodos de trabalho pela burocracia, que dificultam qualquer processo de mudança ou até mesmo de diálogo. Como lembra Herzberg (1997), as instituições públicas transcendem os limites dos gestores que atuam diretamente nas instituições, pois estes processos encontram-se de fato no governo, sendo gerido por indivíduos aos quais os trabalhadores não possuem acesso para o diálogo.

Como afirma Carbone (2000), se referenciando aos gestores das instituições públicas que atuam diretamente no governo, os processos para se obter sucesso no setor público não estão diretamente relacionados com capacidade de inovação, empreendedorismo, ousadia ou competência técnica. Na verdade, a construção histórica da sociedade brasileira acabou por constituir como elemento de sucesso a estes gestores habilidades como conciliar interesses, apaziguar conflitos e demonstrar ser aquilo que na verdade não é. Conforme o mesmo autor, o Brasil historicamente 
nunca interessou-se por desenvolver métodos em busca de indicadores positivos de gestão.

Em contra partida é preciso salientar que os servidores públicos gozam de uma estabilidade de trabalho não existente no setor privado, todavia Traesel e Merlo (2014) ressaltam que, em troca desta estabilidade, os funcionários públicos são sujeitados a práticas perversas de trabalho, conflitos entre interesses políticos e técnicos, sem mencionar a falta de reconhecimento e até mesmo a invisibilidade social destes trabalhadores. Neste ponto a invisibilidade social e depreciação da imagem do servidor público pode gerar um conflito na atividade laboral destes trabalhadores, pois como afirma Andrade et. al. (2017) sobre as instituições públicas de educação, os funcionários que atuam neste setor assumem funções culturais, politicas e sociais, de forma que a visão que a população possui sobre estes funcionários se relaciona e afeta diretamente a função e (in)satisfação destes indivíduos.

\section{ANÁLISE}

A partir da analise dos artigos selecionados pode-se levantar os dados necessários para o desenvolvimento desta pesquisa. Com esta revisão bibliográfica tornou-se evidente que os artigos encontrados possuíam maior foco de estudo nas instituições públicas, já que do total de 24 artigos, 12 tiveram suas pesquisas realizadas neste âmbito e apenas 1 em instituição privada, todavia 8 não informaram em qual setor suas pesquisas foram realizadas e 3 respaldaram-se em revisão bibliográfica e desenvolvimento de teste para mensurar a (in)satisfação dos trabalhadores, conforme o gráfico I. 
Gráfico I: Áreas de Pesquisa.

\section{Gráfico I: Áreas de Pesquisa}

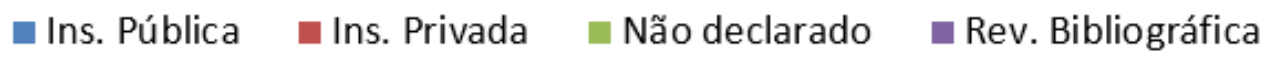

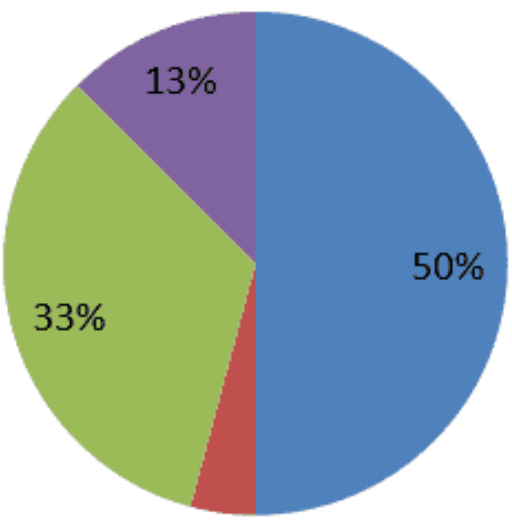

$4 \%$

Fonte: Acervo do Autor (2019)

Com os dados obtidos a partir do gráfico I, é possível evidenciar que os pesquisadores vem demonstrando principal atenção as instituições públicas e aos elementos de (in)satisfação dos servidores que nestes locais atuam. Entretanto vale ressaltar que este dado pode levar a diferentes hipóteses, as quais esta pesquisa não tem intenção de responder, sobre o maior foco de pesquisas na área pública, por exemplo, por quais motivos os pesquisadores vem focando as instituições públicas. Isso se daria pela facilidade de realização das mesmas nestas instituições, a preocupação social com os servidores públicos ou pelo conhecimento, ou suspeita, que estes indivíduos apresentam maiores condições de atingir o estado emocional de (in)satisfações que aqueles que trabalham na iniciativa privada.

Ainda sobre os artigos analisados, pode-se identificar que a soma dos participantes de todas as 21 pesquisas de campo realizadas, pelos artigos selecionados, obteve-se um total de 4.467 indivíduos, divididos conforme a gráfico II. Vale ressaltar que alguns artigos agruparam os participantes, assim atribuindo à área na qual a função era 
executada, por exemplo, a área da educação. Já os participantes "não declarados" pertencem às pesquisas que não informaram de qual área ou função pertenciam os indivíduos que participaram de suas pesquisas.

Gráfico II: Total de profissionais participantes.

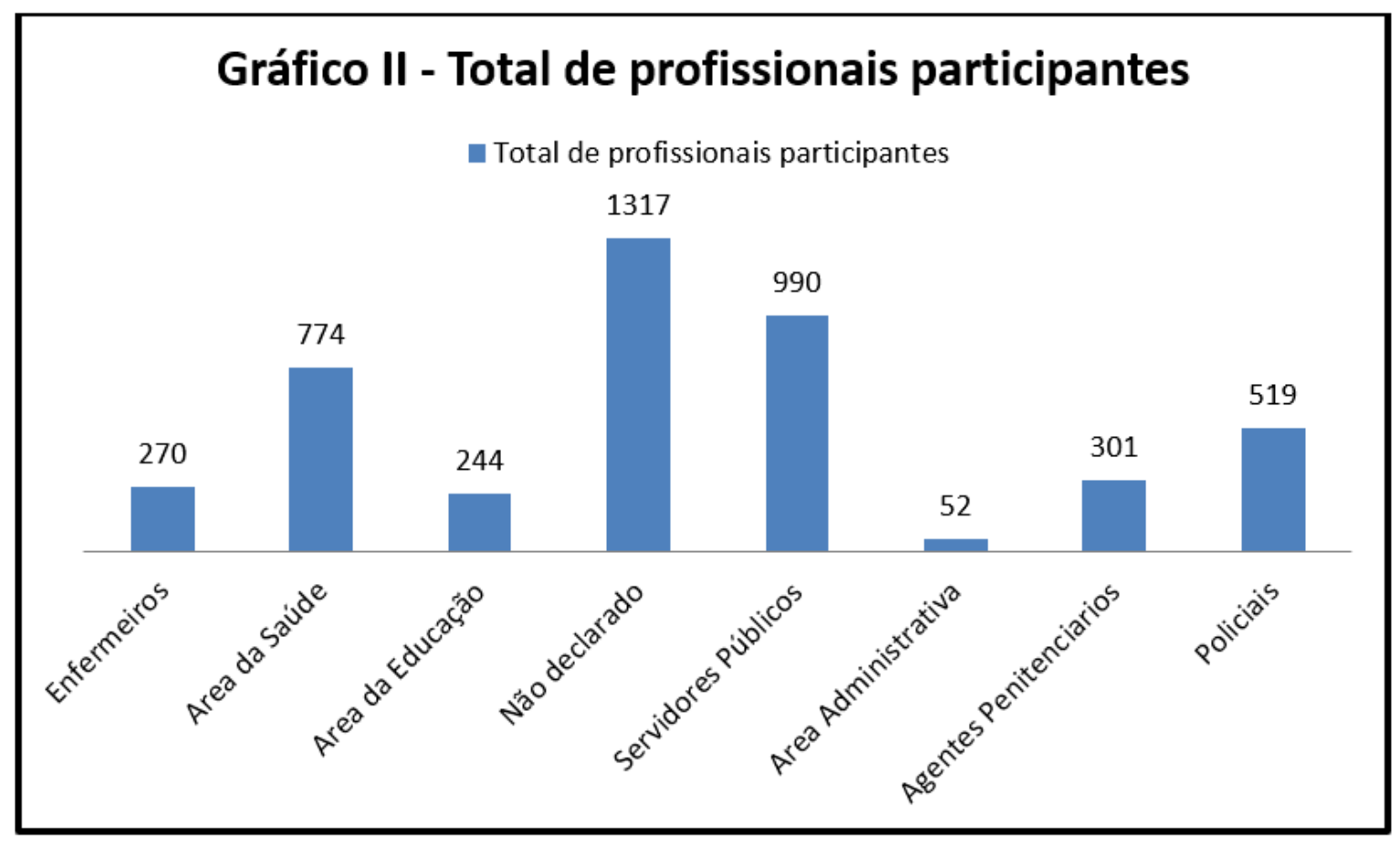

Fonte: Acervo do Autor (2019)

Vale ressaltar que embora os dados apresentados pelo gráfico II demonstrem a quantidade de participantes para cada categoria profissional, isto não indica que as categorias com maior número de indivíduos sejam necessariamente as que contemplem o maior foco dos artigos selecionados, pois cada um dos artigos trabalhou com quantidades diferentes de amostras. O número de agentes policiais, por exemplo, é o quarto maior do gráfico II, entretanto esta categoria profissional foi abordada por apenas um dos artigos selecionados.

Para tornar mais claro em quais áreas os artigos selecionados demonstraram interesse de pesquisa foi elaborado o gráfico III, no qual expõe quantos artigos pesquisaram cada função/área de atuação. 
Gráfico III: Número de artigos por profissão.

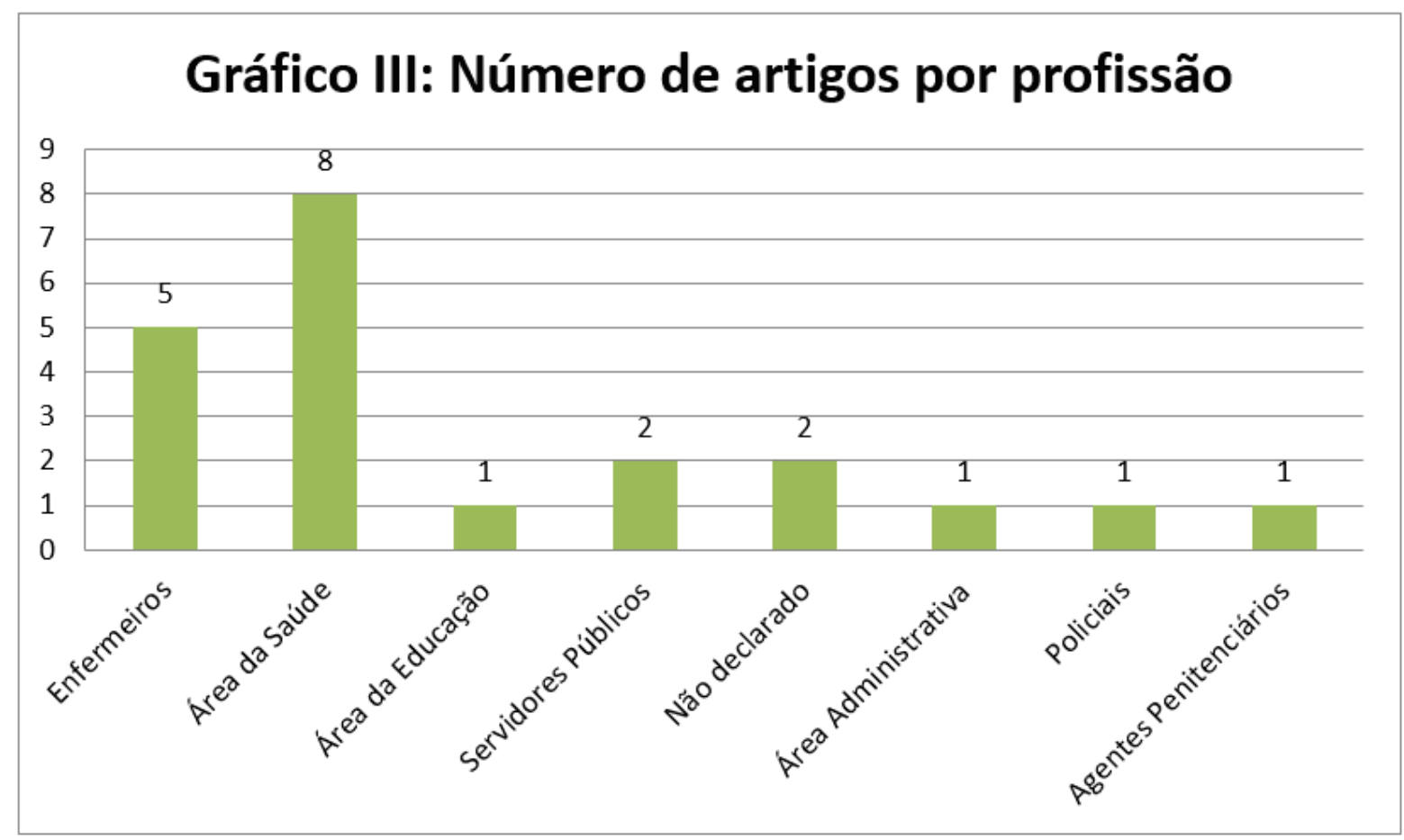

Fonte: Acervo do Autor (2019)

Com analise do gráfico III torna-se demasiadamente importante informar que a área de maior interesse das pesquisas foi no campo da saúde, seguido em segundo lugar pelos artigos que pesquisaram explicitamente os enfermeiros, profissionais que se enquadram no mesmo meio de trabalho. Unindo este dado com os já discutidos com auxílio do gráfico I, podemos entender que o maior campo de coleta sobre dados de (in)satisfação no ambiente de trabalho se deu a partir da colaboração das instituições públicas de saúde, de forma a excluir quase totalmente a participação das áreas da educação, segurança e administrativa.

A partir do fator de pouca relevância dada por pesquisas sobre as áreas que não se enquadram no setor da saúde, podemos refletir que os trabalhadores da educação, segurança e administração acabam por se enquadrar em um grupo de pessoas com invisibilidade cientifica. Como afirma Kemper (2013), assume o papel de invisibilidade aqueles indivíduos compreendidos como incapazes de gerar ou consumir, tornando- 
se assim seres que não tem importância existencial, nem mesmo a relevância em serem explorados.

Continuando os dados levantados a partir da análise dos artigos selecionados para a realização desta pesquisa, temos a apresentação dos elementos citados como fatores de satisfação no ambiente de trabalho expressos no gráfico IV.

Gráfico IV: Elementos de Satisfação.

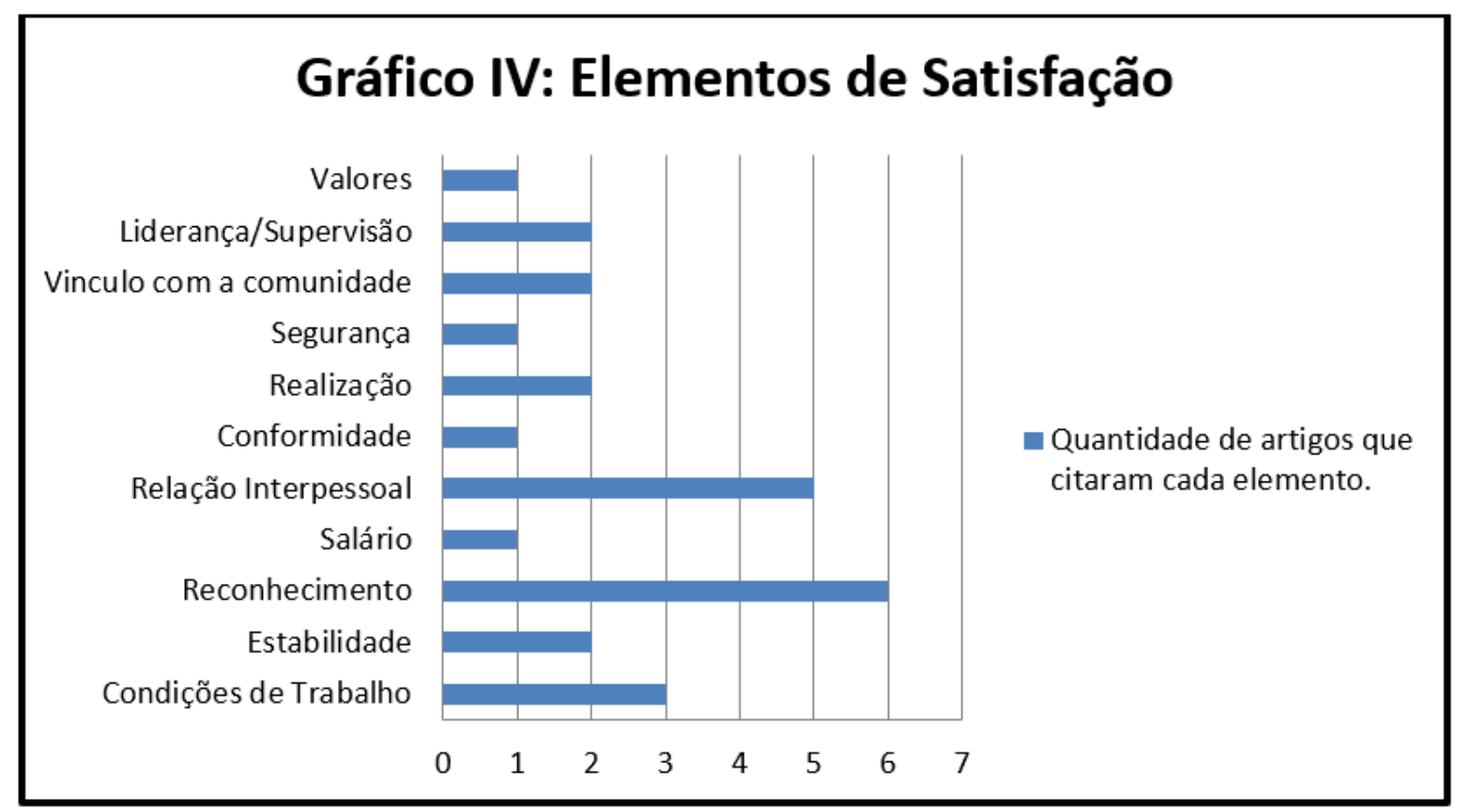

Fonte: Acervo do Autor (2019)

No gráfico IV é possível analisar com clareza que o elemento de satisfação presente na maior parte dos artigos é o reconhecimento profissional, seguido por relações interpessoais, entendido pelos artigos analisados como a relação entre os profissionais da instituição e capacidade de trabalho em equipe. Esta análise é esclarecedora sobre a importância do fator social na busca pela satisfação, de forma que os elementos envolvendo relações de equipe e de reconhecimento evidenciamse sobre outros elementos.

Contrapondo os dados do gráfico IV temos os elementos de insatisfação apresentados a partir do gráfico V. Neste podemos notar que a quantidade de elementos 
referenciados como capazes de gerar a insatisfação se apresentam em maior quantidade que no gráfico anterior, temos ainda o fato que alguns dos elementos são descritos tanto como geradores de satisfação como de insatisfação, como por exemplo, o salário. Desta forma podemos compreender que estes elementos podem desempenhar ambas as funções de acordo com os indivíduos pesquisados, pois estes elementos são influenciados pela subjetividade do indivíduo (SOUZA; MILANI e ALEANDRE, 2015).

Gráfico V: Elementos de Insatisfação.

\section{Gráfico V: Elementos de Insatisfação}

Sistema de Recompensas

Liderança/Supervisão Jornada de Trabalho

Vinculo com a comunidade Burocracia Plano de Carreira Segurança Hierarquia Materiais de Trabalho Autoritarismo Rotatividade Salário

Falta de Pessoal Diferença Formação e Cargo Reconhecimento Condições de Trabalho
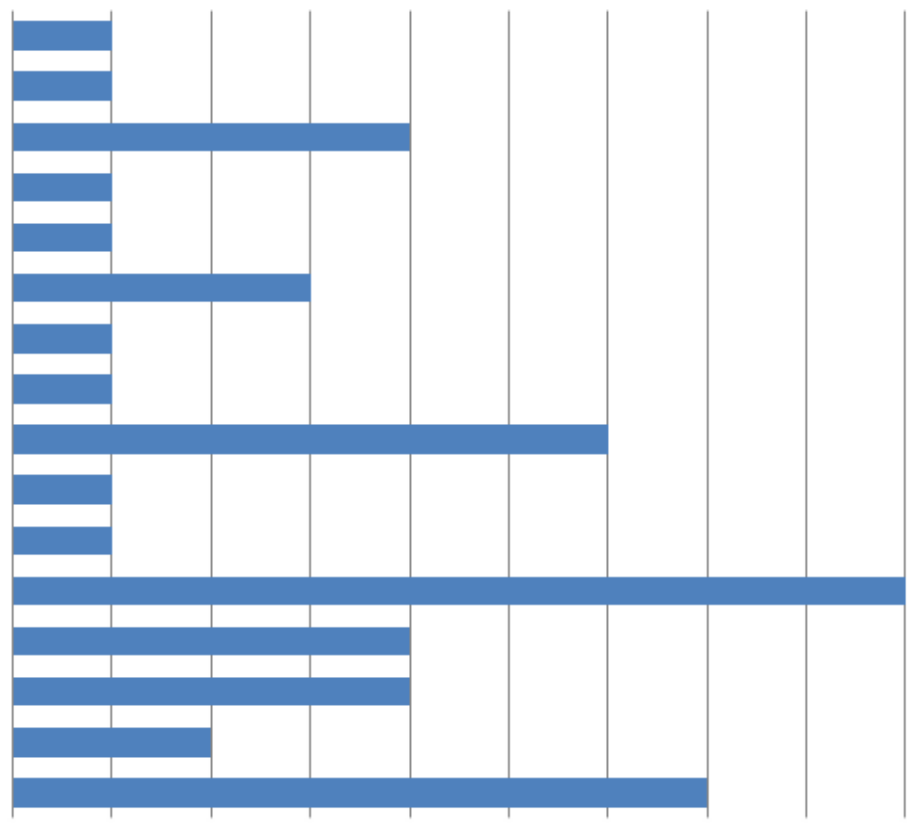

$\begin{array}{lllllllllll}0 & 1 & 2 & 3 & 4 & 5 & 6 & 7 & 8 & 9 & 10\end{array}$

- Quantidade de artigos que citaram cada elemento.

Fonte: Acervo do Autor (2019)

Com a analise do gráfico $\mathrm{V}$, verificamos como os principais fatores de desmotivação o salário, condições de trabalho e materiais de trabalho. Desta forma, contra pondo satisfação e insatisfação, podemos notar que os elementos relacionados a interação social e reconhecimento são os principais geradores de níveis de satisfação, porém 
princípios básico relacionados ao dia a dia do trabalhador como disponibilidade de matérias, condições do ambiente de trabalho e salário são os principais elementos de insatisfação no ambiente de trabalho.

\section{RESULTADOS E CONCLUSÃO}

Com esta pesquisa se conclui que o estado emocional de (in)satisfação se caracteriza como um fator subjetivo, se apresentando de formas diferentes para cada indivíduo. Entretanto é possível compreender que fatores sociais e de auto realização são os principais geradores de satisfação nos trabalhadores. Assim, para que os servidores públicos atinjam tal estado emocional, é preciso o envolvimento profissional entre os membros das instituições públicas, assim como a participação e conscientização da função dos mesmos perante a sociedade. Implica-se aqui também a relevância cientifica e interesse acadêmico sobre pesquisas para a melhoria das condições de trabalho dos servidores púbicos, já que muitos deles aparentam ser invisíveis para a sociedade acadêmica como já discutido pela afirmação Kemper (2013).

É importante ainda, frisar, a relevância de condições favoráveis para o trabalho, como estrutura física, disponibilidade de materiais, reposições de pessoal e planos/benefícios de carreira. Estes elementos são de importante atenção, pois podem se apresentar como geradores de insatisfação, de forma que a distribuição correta destes elementos podem evitar a falta de satisfação dos servidores púbicos. Neste ponto revela-se a importância da participação dos órgãos municipais e governamentais para a satisfação de seus servidores, pois são estes órgãos que controlam a disposição e disponibilidade destes elementos nas instituições públicas.

Assim conclui-se que a conscientização e participação tanto social como dos órgãos municipais/governamentais são de suma importância na busca da satisfação dos servidores púbicos. Desta forma, respondendo a problemática desta pesquisa, conclui-se que o estado emocional de satisfação nos servidores púbicos pode ser atingido, porém é influenciado diretamente pela sociedade, pessoas para quem os servidores públicos prestam serviços, assim como pelos órgãos municipais e governamentais que gerem o trabalho dos servidores públicos. Entendendo-se por fim 
que o respeito, reconhecimento das funções e condições favoráveis de trabalho, se fazem necessárias para a boa atuação, qualidade de vida e satisfação dos servidores públicos.

\section{REFERÊNCIAS}

ANDRADE, T. et al . Comportamento de cidadania organizacional: um olhar à luz dos valores e da satisfação no trabalho. Rev. bras. gest. neg., São Paulo, v. 19, n. 64, p. 236-262, $\quad$ Apr. $2017 \quad$ Disponível em:

<http://www.scielo.br/scielo.php?script=sci_arttext\&pid=S1806-

$48922017000200236 \&$ Ing=en\&nrm=iso >. Acesso em 09 jun. 2019.

BRASIL, Lei oํ 9.527, 10 de dezembro de 1997, Altera dispositivos das Leis nํㅗ 8.112, de 11 de dezembro de 1990, 8.460, de 17 de setembro de 1992, e 2.180, de 5 de fevereiro de 1954, e dá outras providências. Disponível em: <http://www.planalto.gov.br/ccivil_03/LEIS/L9527.htm\#art1>. Acesso em 13 abr. 2019.

BRASIL, Rio Grande do Sul, Lei ํo 10.098, 03 de fevereiro de 2014, Dispõe sobre o estatuto e regime jurídico único dos servidores públicos civis do Estado do Rio Grande do Sul. Disponível

em: <http://www.al.rs.gov.br/filerepository/repLegis/arquivos/10.098.pdf>. Acesso em 13 abr. 2019.

BRASIL, São Paulo, Lei no 10.261, 28 de outubro de 1968, Dispõe sobre o Estatuto dos Funcionários Públicos Civis do Estado. Disponível em: <https://www.al.sp.gov.br/repositorio/legislacao/lei/1968/lei-10261-28.10.1968.html>. Acesso em 13 abr. 2019.

CARBONE, P. P. Cultura organizacional do setor público brasileiro: desenvolvendo uma metodologia de gerenciamento de cultura. Revista de Administração Pública,
v.
34 ,
n.
2 ,
2000 .
Disponível
em: 
<http://bibliotecadigital.fgv.br/ojs/index.php/rap/article/view/6273/4864>. Acesso em 23 jun. 2019.

FORTE, E. C. N.; PIRES, D. E. P. ENFERMEIRAS NA ATENÇÃO BÁSICA: ENTRE A SATISFAÇÃO E A INSATISFAÇÃO NO TRABALHO. Trab. educ. saúde, Rio de Janeiro , v. 15, n. 3, p. 709-724, dez. 2017 . Disponível em $<$ http://www.scielo.br/scielo.php?script=sci_arttext\&pid=S198177462017000300709\&lng=pt\&nrm=iso $>$. Acesso em 09 jun. 2019.

HERZBERG, F. Novamente: Como se faz para motivar funcionários? In: BERGAMINI, C. W., CODA, R. (Org.). Psicodinâmica da Vida Organizacional: Motivação e Liderança, São Paulo, 2. ed., p. 108-129. Disponível em: <https://nc400.files.wordpress.com/2012/02/herzberg-19971975.pdf>. Acesso em 22 mar. 2019.

HORA, G. P. R.; RIBAS JUNIOR, R.; SOUZA, M. A. Estado da Arte das Medidas em Satisfação no Trabalho: Uma Revisão Sistemática. Temas em Psicologia, Ribeirão

Preto, v. 26, n. 2, p. 971-986, jun. 2018 . Disponível em $<$ http://www.scielo.br/scielo.phpscript=sci_arttext\&pid=S235818832018000200971\&l ng=pt\&nrm=iso >. Acesso em 08 abr. 2019.

IPEA, Ocupação no Setor Publico Brasileiro, no110, p. 25, ano 2011. Disponível em: $<$ https://ipea.gov.br/portal/images/stories/PDFs/comunicado/110908_comunicadoipe a110.pdf>. Acesso 07 abr. 2019.

KEMPER, M. L. C. Invisibilidade, identidade e laço social na contemporaneidade: sobre a exclusão nas esferas psíquica e social. Cad. psicanal., Rio de Jeneiro, v. 35, n. 29, p. 105-125, dez. 2013 . Disponível em: <http://pepsic.bvsalud.org/scielo.php?script=sci_arttext\&pid=S1413$62952013000200007 \&$ Ing=pt\&nrm=iso>. Acesso em 23 jun. 2019.

MARQUES, A. L.; BORGES, R.; REIS, I. C. Mudança organizacional e satisfação no trabalho: um estudo com servidores públicos do estado de Minas Gerais. Rev. Adm. 
Pública, Rio de Janeiro, v. 50, n. 1, p. 41-58, fev. 2016 . Disponível em: $<$ http://www.scielo.br/scielo.php?script=sci_arttext\&pid=S003476122016000100041\& Ing=pt\&nrm=iso $>$. Acesso em 09 jun. 2019.

PILATTI, L. A. Qualidade de vida no trabalho e teoria dos dois fatores de Herzberg: possibilidades-limite das organizações. Rev. Brasileira de Qualidade de Vida, Ponta Grossa, v. 4, n. 1, p. 18-24, jan./jun. 2012. Disponível em: < https://periodicos.utfpr.edu.br/rbqv/article/view/1195/801>. Acesso em 23 mar. 2019.

PORTAL DO GOVERNO, Mulheres Representam 52\% dos Servidores do Estado de São Paulo, ano 2017.2 Disponível em: <http://www.saopaulo.sp.gov.br/spnoticias/mulheres-representam-52-dos-servidoresdo-estado-de-sao-paulo/>. Acesso em 07 abr. 2019.

SA, A. M. S.; MARTINS-SILVA, P. O.; FUNCHAL, B. Burnout: o impacto da satisfação no trabalho em profissionais de enfermagem. Psicol. Soc., Belo Horizonte, v. 26, n. 3, p. 664-674, Dec. 2014. Disponível em: <http://www.scielo.br/scielo.php?script=sci_arttext\&pid=S0102$71822014000300015 \&$ Ing=en\&nrm=iso $>$. Acesso em 09 jun. 2019.

SILVA, E. D. e MENEZES, E. M. Metodologia da Pesquisa e Elaboração de Dissertação. 4aed. Florianópolis: Rev. Atual, 2005, 139 p. Disponível em: $<$ https://projetos.inf.ufsc.br/arquivos/Metodologia_de_pesquisa_e_elaboracao_de_te ses_e_dissertacoes_4ed.pdf $>$. Acesso em 22 mar. 2019.

SILVEIRA, D. T., CÓRDOVA,F. P., A Pesquisa Científica. In: GERHARDT, T. E., SILVEIRA, D. T. (Org.). Métodos de Pesquisa, Porto Alegre, 1 ed., p. 31-42. Disponível em: <http://www.ufrgs.br/cursopgdr/downloadsSerie/derad005.pdf>. Acesso em 13 abr. 2019.

SORATTO, J. et al. INSATISFAÇÃO NO TRABALHO DE PROFISSIONAIS DA SAÚdE NA ESTRATÉGIA SAÚdE DA FAMÍLIA. Texto contexto enferm., Florianópolis , v. 26, n. 3, e2500016, 2017 . Disponível em: 
$<$ http://www.scielo.br/scielo.php?script=sci_arttext\&pid=S0104$07072017000300325 \&$ Ing=pt\&nrm=iso>. Acesso em 09 jun. 2019.

SOUZA, D. I., et. al., Manual de Orientações Para Projetos de Pesquisa., Novo Hamburgo, FESLSVC, p.55, 2013. Disponível em: $<$ http://www.liberato.com.br/sites/default/files/manual_de_orientacoes_para_projetos _de_pesquisa_1.pdf>. Acesso em 13 abr. 2019.

SOUZA, A. C.; MILANI, D.; ALEXANDRE, N. M. C. Adaptação cultural de um instrumento para avaliar a satisfação no trabalho. Rev. bras. saúde ocup., São Paulo v. 40, n. 132, p. 219-227, dez. 2015 . Disponível em $<$ http://www.scielo.br/scielo.php?script=sci_arttext\&pid=S0303$76572015000200219 \&$ Ing=pt\&nrm=iso>. Acesso em 09 jun. 2019.

TAMBASCO, L. P. et al . A satisfação no trabalho da equipe multiprofissional que atua na Atenção Primária à Saúde. Saúde debate, Rio de Janeiro , v. 41, n. spe2, p. 140151, Jun, 2017. em: $<$ http://www.scielo.br/scielo.php?script=sci_arttext\&pid=S01031042017000600140\&Ing=en\&nrm=iso >. Acesso em 08 Abr. 2019.

TRAESEL, E. S.; MERLO, A. R. C. "Somos Sobreviventes": vivências de servidores públicos de uma instituição de seguridade social diante dos novos modos de gestão e a precarização do trabalho na reforma gerencial do serviço púbico. Caderno de Psicologia Social do Trabalho, v. 17, n. 2, 2014. Disponível em: <http://www.revistas.usp.br/cpst/article/view/112344/110308>. Acesso em 23 jun. 2019.

Enviado: Setembro, 2019.

Aprovado: Março, 2020. 